\title{
ПОЛИТОЛОГИЧЕСКИЕ НАУКИ
}

\section{ГЕНДЕРНАЯ ПОЛИТОЛОГИЯ}

Woman in Russian Society

2019. No. 1. P. 5-15

DOI: $10.21064 / \mathrm{WinRS} .2019 .1 .1$
Женщина в российском обществе

2019. № 1. C. 5-15

ББК $66.3(7 \mathrm{Coe}), 4$

DOI: $10.21064 /$ WinRS.2019.1.1

\section{МЕЖДУ КОЛЯСКОЙ И НОУТБУКОМ: РЕАДИЗАЦИЯ ПОЯИТИКИ ГЕНДЕРНОГО РАВЕНСТВА В США}

\author{
Н. А. Шведова \\ Институт США и Канады, Российская академия наук, г. Москва, Россия, \\ n.shvedova2015@yandex.ru
}

\begin{abstract}
Рассматривается, как и в какой степени американская демократия решает проблемы в контексте создания гендерного баланса и возможностей для равенства полов; какова характеристика условий, благоприятствующих функционированию реальной демократии и ее дальнейшему совершенствованию с точки зрения гендерного подхода. Автор считает, что в настоящее время американские женщины обладают значительными рычагами власти и влияния как на собственные судьбы, так и на приоритеты внутренней и внешней политики государства. Последняя президентская гонка (2016 г.) четко выявила особое значение гендерного фактора в ней, что формирует новые характеристики политической культуры в стране. В развитии женского движения США наблюдаются явно выраженные тенденции к вовлечению в политический процесс и законотворческую деятельность женщин, к поиску контактов и партнерств внутри самого гражданского общества. Вместе с тем конституционные и репродуктивные права женщин подвергаются опасности при нынешней республиканской администрации Д. Трампа, которому вменяют в вину и подрыв лидерства женщин.
\end{abstract}

Ключевые слова: гендерное равенство, гендерная справедливость, женский марш, электорат, Совет Соединенных Штатов и Канады по улучшению положения женщин предпринимательниц и лидеров бизнеса, индекс гендерного разрыва.

(С) Шведова Н. А., 2019

Окончание. Начало в предыдущем номере. 


\title{
BETWEEN THE BABY AND LAPTOP: IMPLEMENTATION OF GENDER EQUALITY POLICIES IN THE USA
}

\author{
N. A. Shvedova \\ Institute for the U. S. and Canadian Studies, Russian Academy of Sciences, \\ Moscow, Russian Federation, n.shvedova2015@yandex.ru
}

How and to what extent the American democracy solves problems in the context of creating a gender balance and opportunities for gender equality? What is the characteristic of the conditions that favors the functioning of real democracy and its further improvement in terms of a gender approach? The author believes that at present the American women have significant levers of power and influence on the formation of their own destiny, as well as on the priorities of the domestic and foreign policies of the state. The last presidential campaign (2016) clearly revealed the special significance of the gender factor, which forms new characteristics of political culture in the country. There are clearly pronounced tendencies in the development of women's movement in the USA to involve women in the political process and lawmaking activities, to seek contacts and partnerships within the civil society itself. At the same time, the constitutional rights of women (weakening protection from gender-based violence, reproductive rights, reproductive autonomy, "assault" on reproductive rights, infringement on women's legal rights) are at risk under the current Republican administration of D. Trump, which is said to pursue the policy undermining women's leadership.

Key words: gender equality, gender justice, women's march, electorate, United States Canada Council for Advancement of Women Entrepreneurs and Business Leaders, Global Gender Gap Index.

\section{Американки в обстоятельствах экономической политики администрации Д. Трампа}

Президент-республиканец Д. Трамп объявил цель: достичь 3 \%-го роста ВВП. При этом он подчеркнул, что хотелось бы сосредоточиться на увеличении количества женщин в экономике. Критики позиции президента отмечают непоследовательность его намерений. «Вероятно, он мог бы добиться цели гораздо быстрее, если бы попытался сделать больше по проблеме равной оплаты и предоставить субсидии по уходу за детьми. По настоянию своей дочери Иванки он говорил поверхностно о возможном введении субсидий по уходу за детьми и оплачиваемого отпуска, но пока его планы довольно жалкие», - заявила Х. Хартманн, президент Института исследований политики женщин — Institute for Women's Policy Research (организация, которая готовит ежегодный доклад об экономическом статусе американских женщин в каждом штате). Она считает, что президент «просто сделал шаг назад» в решении проблемы разрыва в оплате труда, «отменив правило, согласно которому предприятия должны сообщать о заработной плате по полу...» (цит. по: [Cooney, 2017]).

Были заблокированы гарантии прозрачности оплаты труда, поскольку Д. Трамп отменил соответствующее постановление. Требование к федеральным 
подрядчикам, которое предусматривало предоставление сотрудникам базовой информации об оплате их труда, включая отработанные часы, сверхурочные и любые выплаты, было исключено. Такая информация имеет решающее значение для всех работников, особенно женщин, которые с большей вероятностью заняты в почасовом режиме. Отмена Д. Трампом постановления о справедливой оплате труда и безопасных рабочих местах облегчила жизнь федеральным подрядчикам, которые постоянно допускали нарушения, связанные с дискриминацией по признаку пола и несоблюдением других трудовых норм, однако могли продолжать получать федеральное финансирование.

Президент Д. Трамп принял решение об отсрочке реализации так называемых правил сверхурочной работы, введенных при администрации Б. Обамы. Многие американские эксперты считают, что такое решение способствует разрушению экономической безопасности семьи, поскольку при сохранении в силе упомянутых правил 3,2 млн американок попали бы под их юрисдикцию, и это было бы для них выгодно за счет права получать сверхурочные.

В чем суть изменений? Дело в том, что в 2015 г. администрация демократа Б. Обамы предложила корректировку оплаты труда. Намеченные изменения должны были увеличить в 2016 г. порог зарплаты, предусмотренный для оплаты сверхурочных часов, до 970 долл. США в неделю. Это означало, что работники, получающие годовой оклад в размере 50440 долл. США или менее, имели бы право на оплату сверхурочной работы. В 2015 г. этот порог составлял 455 долл. США в неделю. Последний раз порог обновлялся в 2004 г., что дало основание администрации Б. Обамы заявить о необходимости его пересмотра, так как он был подорван инфляцией. В 2015 г. сверхурочные выплачивали работникам, чья ежегодная заработная плата составляла 23660 долл. США или менее, если они трудились более 40 часов в неделю [Mai-Duc, 2015]. Эти правила не применялись к работникам, которые классифицировались как исполнительные, административные или профессиональные. Например, наблюдатели (супервайзеры) в ресторане быстрого питания могли не иметь права на сверхурочную работу, даже если они выполняли большую часть тех же функций, что и работники кухни. (для сравнения: в 1975 г. более 60 \% наемных работников имели право на оплату сверхурочной работы).

Согласно данным Совета по внутренней политике Белого дома, в 2015 г. эти правила действовали для менее $8 \%$ работников, занятых полный рабочий день. «Фактически, мы видели, что инфляция отменяет правила, которые вступили в силу несколько десятилетий назад», - сказал X. Шайкен, экономист по труду и профессор Калифорнийского университета в Беркли (цит. по: [ibid.]). Администрация Б. Обамы, прибегнув к процедуре исполнительных указов президента, приняла установку на проведение «линии с обновленным лимитом зарплаты», которая помогла бы сотрудникам, обычно классифицируемым как менеджеры, но зарабатывающим всего 25 тыс. долл. в год [ibid.]. Следует подчеркнуть, что Закон о справедливых трудовых нормах от 1938 г. наделяет президента широкими полномочиями устанавливать правила, не обращаясь за санкцией к Конгрессу США. Министерство труда по указанию президента может вводить новые правила в рамках федерального нормотворческого процесса. Предлагаемые правила публикуются в Федеральном реестре, после чего 
Министерство труда соблюдает 60-дневный период обсуждения. Заинтересованные стороны и граждане могут представить комментарии по этой инициативе. Администрация должна рассмотреть их, прежде чем окончательное правило будет санкционировано.

Администрация Б. Обамы подчеркивала, что предлагаемые изменения затронут примерно 5 млн рабочих страны. Должностные лица заявляли об охвате новыми правилами почти 40 \% штатных сотрудников, работающих полный рабочий день. Министр труда Т. Перес отметил, что новые правила могут «добавить до 1,3 млрд долл. в карманы рабочих по всей стране» (цит. по: [ibid.]). Ясно, что эта мера не вызвала энтузиазма у работодателей: промышленные и бизнес-группы в значительной степени осудили предложенные изменения. Президент Д. Трамп отложил реализацию этих правил, используя ту же процедуру, к которой прибегал президент Б. Обама, когда их вводил. В результате такого решения особенно пострадают цветные американки и женщины с детьми, которые в большей части попадали бы под действие этих правил [Hartmann et al., 2015]. Хотя Д. Трамп иногда высказывался в поддержку равной оплаты труда женщин и мужчин на протяжении всей своей избирательной кампании, его администрация не предложила никаких конкретных мер по укреплению таких норм [Levey, 2017]. В планах Д. Трампа сокращение бюджета Министерства труда США на $21 \%$, или 2,5 млрд долл. Это сокращение повлияет на соблюдение условий труда и защиту рабочих семей [Levintova, 2017].

\section{Сокращение ассигнований на здравоохранение и социальные услуги}

Перечень объектов «нападок» администрации Д. Трампа на социальное благополучие включает медицинское обслуживание американок, репродуктивные права женщин, социальные программы и программы социального вспомоществования, направленные в большинстве случаев на помощь американским женщинам, поскольку их больше среди малоимущих. Вызывают тревогу у американок персональные назначения на ключевые позиции в государстве лиц, политическая биография и репутация которых свидетельствуют об их «антиженской» направленности. Возникает угроза потери многих позитивных начинаний, которые были реализованы при администрации Б. Обамы.

В бюджете администрации Д. Трампа предлагается сократить финансирование на сумму 15 млрд долл. США офиса, ответственного за реализацию Закона о доступном здравоохранении и обеспечение женщинам и семьям доступа к жизненно важным службам здравоохранения. Это означает ограничение доступа к услугам по охране репродуктивного здоровья в рамках программ «Медикейд» и «Медикэр», а также лишение финансирования учреждения «Национальные институты здравоохранения» (National Institutes of Health), Управления по контролю за продуктами и лекарствами (Food and Drug Administration) и Центра по контролю и профилактике заболеваний (Center for Disease Control and Prevention) [Levey, 2017].

Вмешательство в сферу предоставления медицинских услуг по прерыванию беременности. Проект Д. Трампа «Американский закон о здравоохранении», как справедливо подчеркивают многие американские аналитики, встанет препятствием между пациентом и производителем медицинских услуг и ограничит 
выбор женщин из-за отказа в страховании на случай прерывания беременности на частном страховом рынке.

Администрация Д. Трампа подписала законопроект, в соответствии с которым осуществлен отказ от предоставления женщинам критически важных репродуктивных, образовательных и консультационных услуг, связанных с планированием семьи и контрацепцией, т. е. ограничена доступность прерывания беременности. Речь идет о том, что штатам теперь можно блокировать финансирование для поставщиков медицинских услуг по прерыванию беременности с нефедеральными средствами, в том числе для программы «Планируемое родительство».

В бюджете Д. Трампа предлагается сократить финансирование профилактики подростковой беременности, в частности урезать на 50 млн долл. средства Программы профилактики беременности подростков (Teen Pregnancy Prevention Program), которая ранее продемонстрировала свою эффективность [ibid.]. Проект «Американский закон о здравоохранении» также исключает педиатрические услуги: страхование семьи не распространяется на вакцины, консультации окулистов и профилактические визиты здоровых детей к врачу. Это будет непропорционально влиять на женщин, которые часто берут на себя основную ответственность за обеспечение семьи необходимой медицинской помощью. У сторонников права на выбор вызывают тревогу призывы к принятию Поправки Хайда как постоянной ${ }^{1}$. В соответствии с ней, происходит ограничение охвата медицинскими услугами по прерыванию беременности, которые предоставляют получателям по программе медицинского вспомоществования «Медикейд». И президент Д. Трамп, и вице-президент М. Пенс пообещали добиться, чтобы Поправка Хайда стала постоянной. Кодификация поправки создаст опасный прецедент и надолго подвергнет женщин, получающих медицинские пособия по «Медикейд», ограничениям без регулярного обзора их воздействия, считают сторонники защиты права женщин на выбор.

Исследования показали, что от 18 до 33 \% женщин, которые имеют право на участие в программе «Медикейд» и хотели бы прервать беременность, но проживают в штатах, где не предоставляют финансирование на эти медицинские услуги, вынуждены рожать [Access Denied..., 2017] (речь идет о женщинах репродуктивного возраста - 15-44 года). Проект «Американский закон о здравоохранении», который поддерживает Д. Трамп, сократит финансирование программы «Медикейд» на 880 млрд долл., хотя 19 млн женщин полагаются на нее при медицинском страховании. Сокращения особенно затронут интересы беременных женщин, матерей и детей [Park et al., 2017].

Уход за детьми. Несмотря на риторику о заботе о детях и молодежи, бюджет Д. Трампа, как справедливо подчеркивают эксперты, свидетельствует об обратном [Frothingham, Phadke, 2017]. Предлагаемые меры сокращают возможности для многих американских детей, особенно из малоимущего сегмента семей. Это подтверждает уменьшение на 1,2 млрд долл. средств для учебных центров XXI в. на местах (в комьюнити) и для летних программ, которые обеспечивают дошкольное и послешкольное обслуживание 1,6 млн детей по всей стране и позволяют родителям работать.

\footnotetext{
${ }^{1}$ Поправка, названная в честь ее главного инициатора республиканца-конгрессмена Г. Хайда из штата Иллинойс, была принята палатой представителей 30 сентября 1976 г.
} 
Администрация Д. Трампа предполагает сокращение на 18 \% средств для Министерства здравоохранения и социального обеспечения, в результате этого 160 тыс. детей будут лишены возможности пользоваться программой «Начальный старт». Кроме того, будут ликвидированы рабочие места для 40 тыс. человек, в основном женщин, которые были задействованы в этой сфере [America First..., 2018]. В планах администрации Д. Трампа снижение финансирования государственных школ, если они не соответствуют стандартам качества, путем перевода из них средств в частные школы. Предлагается также ликвидация Корпорации национальной и общественной службы, которая финансировала клубы мальчиков и девочек Америки, охватывающие около 1,8 млн человек каждый год [Measuring the Impact... , 2016].

\section{Механизм гендерного равенства в США: новые аспекты}

Понятие «механизм» принято мировым сообществом для обозначения всего институционального устройства, созданного для строительства гендерного равенства в обществе и государстве. Национальный механизм гендерного равенства характеризуется четырьмя основными интегральными компонентами, или измерениями, признаками, - законодательно-правовым, структурно-организационным, содержательным и просветительско-образовательным. Национальный механизм - это совокупность взаимосвязанных частей, каждая из которых не способна не только работать автономно, но и представлять собой целостный организм - систему, выполняющую функцию по строительству гендерного равенства.

В США юридическая база социально-экономического статуса женщин была заложена еще в 60-х гг. XX в. и получила развитие в виде поправок в 7090-х гг. Важнейшие нормативные акты, принятые федеральным высшим законодательным органом страны, касались широкого круга вопросов жизнедеятельности женского населения страны. В период правления Б. Клинтона (19942000 гг.) произошли заметные позитивные изменения в статусе американских женщин. В то время удалось смягчить остроту социальных проблем, отражающихся прежде всего на женщинах. Этому способствовала политика, проводимая демократической администрацией, нацеленная на укрепление среднего класса Америки и поддержку семейных ценностей.

Вместе с тем в женском движении сохраняются проблемы консолидации и выработки общей стратегии. При широком разнообразии направлений и интересов в нем координация действий по решению политических задач связана с определенными трудностями (например, принятие Поправки о равных правах женщин, ратификация Конвенции ООН о ликвидации всех форм дискриминации в отношении женщин). Женскому движению США свойственна «инерция достигнутого успеха», которая может оказаться помехой для объединения усилий в случае ревизии властью своей политики по «женскому вопросу».

В состав органов государственной власти, в ведении которых находятся вопросы реализации программ гендерного равенства, входят специальные подразделения в министерствах и ведомствах, занимающиеся проблемами женщин и девочек: Бюро по женскому найму Министерства труда, Федеральная 
контрактная программа для женщин малого бизнеса США, Бюро женского делового предпринимательства в рамках Администрации по малому бизнесу.

В каждом штате была введена штатная должность координатора по равенству полов, основная задача которого - разрушение гендерных стереотипов о традиционно «мужских» и «женских» профессиях. Специально оговаривалось положение, открывающее возможность для женщин - домашних хозяек получить профессиональные знания. Федеральное правительство выделяло средства штатам для организации центров по профессиональной подготовке.

Бюро по женскому найму Министерства труда в течение всего времени своего существования играло роль инициатора социальных движений. История его деятельности имеет длительный период: оно было создано еще в 1920 г. Это подразделение бюрократической федеральной машины оказало заметное влияние на развитие женских интересов в трех направлениях: создании идеологии о месте женщин в рабочей силе, установлении более тесных связей среди женщин-трудящихся, выработке государственного курса решения «женского вопроса». Бюро всегда было и остается важнейшим источником статистических данных о положении женщины и ее месте в сфере трудовых ресурсов.

Бюро женского делового предпринимательства, механизм государственной поддержки развития женского предпринимательства, было сформировано в 1980 г. в рамках Администрации по малому бизнесу (ранее все федеральные департаменты и агентства получили указание обеспечить режим наибольшего благоприятствования для деловых инициатив, выдвинутых женскими предпринимательскими кругами).

Совет по делам женщин и девочек Белого дома, созданный в период второй администрации демократа Б. Обамы, сосредоточился на конкретных вопросах межсекторального взаимодействия, исследуя то, как «гендер пересекается с другими идентичностями, например расой» и «с чем сталкиваются женщины из групп с низким доходом, перед какими трудностями оказываются цветные женщины, трансгендеры, американки с ограниченными возможностями» (слова К. Дессурс, консультантки по вопросам политики, ориентированной на продвижение справедливости для цветных женщин и девочек, цит. по: [National Center for Education Statistics, 2015]).

В 2009 г. Б. Обама представил Совету Белого дома по делам женщин и девочек целый пакет различных инициатив для оценки основных политических курсов и законодательства (например, Закон о доступном здравоохранении), их воздействия на примерно половину населения. Иными словами, Совет производил гендерный анализ законодательной инициативы, что происходило в полном соответствии с действием механизма гендерного равенства.

В марте 2017-го судьба Совета оставалась еще нерешенной. Между тем веб-сайт был уничтожен, так же как и сайты многих других инициатив Б. Обамы, сразу после передачи власти. Т. Тчен, другая сопредседательницей Совета - В. Джарретт и остальные сотрудники покинули Белый дом вместе с Б. Обамой, который передал президентский жезл новому, 45-му президенту США. Но многие чиновники, с которыми они сотрудничали в федеральных агентствах и ведомствах, остались. 
Во время своего выступления в Конгрессе США 28 февраля 2017 г. Д. Трамп сообщил о создании Совета Соединенных Штатов и Канады по улучшению положения женщин - предпринимательниц и лидеров бизнеса, решение об организации которого президент принял в январе 2017-го совместно с премьер-министром Канады Дж. Трюдо. По мнению экспертов, Совет Кушнера Трампа не заменит деятельности Совета Белого дома по делам женщин и девочек. По данным «Associated Press», офис Дж. Трюдо обратился к команде Трампа, чтобы начать совместные действия по подготовке организационной структуры. И. Трамп, дочь президента, активно включилась в работу целевой группы. Чем деятельность нового Совета будет отличаться от работы различных структур по расширению прав и возможностей женщин-предпринимательниц, созданных за последние десятилетия, пока сказать сложно.

\section{Некоторые итоги}

Анализ ситуации в США в контексте гендерного баланса и гендерного равенства фиксирует главную перемену, которая произошла в стране преимущественно благодаря неустанной борьбе американских женщин за свои права, и убеждает в том, что основополагающее содержательное требование женского движения - признание в женщине полноценного человека, личности - получило широкое распространение в общественном сознании. При этом эволюция демократического женского движения в Соединенных Штатах осуществляется по траектории нарастания веса и влияния в политике и общественной жизни страны. Об этом свидетельствует тот факт, что в повестку дня государства включаются первоочередные задачи, нацеленные на достижение гендерного равенства.

В настоящее время американские женщины обладают значительными рычагами власти и влияния на формирование как собственной судьбы, так и приоритетов внутренней и внешней политики государства. Последняя президентская гонка (2016 г.) четко выявила особое значение гендерного фактора в ней, что формирует новые характеристики политической культуры в стране.

Вместе с тем до сих пор Соединенные Штаты не ратифицировали Конвенцию ООН о ликвидации всех форм дискриминации в отношении женщин (в 2017 г. ее одобрили 189 стран), оказавшись единственной промышленно развитой державой устойчивой демократии в числе немногих других (например, Тонга и Палау), которые не одобрили эту конвенцию, известную в мире как Билль о правах женщин. Перед американским женским демократическим движением стоит актуальная задача добиться ратификации Поправки о равных правах, для одобрения которой не хватило всего лишь трех штатов в 1982 г.

Значительное количество американских женщин участвуют в избирательных гонках. Поражение Х. Клинтон стало для них стимулирующим фактором активизации своего участия в борьбе за выборные должности. Об этом свидетельствуют и данные организации «Список ЭМИЛИ»²: если за десять месяцев

\footnotetext{
${ }^{2}$ «Список ЭМИЛИ» (EMILY's List) - некоммерческая организация, занимающаяся сбором средств для выдвижения женщин - членов Демократической партии на руководящие должности. ЭМИЛИ - не имя, а аббревиатура образного выражения Ранние деньги работают как дрожжи (Early Money Is Like Yeast).
} 
до выборов 2016 г. около тысячи женщин выразили готовность участвовать в выборах на соответствующий пост, то после победы Д. Трампа это число выросло до более чем 22 тыс. человек, т. е. увеличилось в 22 раза. 291 женщина только от Демократической партии участвует в гонке за места в палату представителей, a 25 женщин-демократок баллотируются в Сенат, в два раза больше по сравнению с предыдущими выборами.

Демократическая система США, переживая кризисное состояние, вместе с тем демонстрирует способность к саморегулированию политического процесса. Очевидно, что в США курс развития демократии внутри страны корректируется благодаря принципу сдержек и противовесов. Объективный результат - расширение круга субъектов политического процесса, что ограничивает концентрацию политической власти на одном фланге. Женщины и молодое поколение - новые игроки этого процесса, выступающие на передний план. В то же время выборы обнажили достаточно резкую тенденцию к поляризации электората. Повторившиеся марши протестов - свидетельство нерешенных проблем, которые особенно чувствительно сказываются на женском населении и не позволяют утверждать, что в стране достигнуто полное и безусловное гендерное равенство.

Гарантия недопущения острых полярных противостояний - двухпартийная система в США, а достижение компромиссных вариантов зачастую противоположных решений - сложнейшая политическая задача, которую неизбежно придется реализовать на пути налаживания конструктивного социального мира и стабильности.

Женское движение выполняет важнейшую функцию в политике США: оно артикулирует новые ценности массового сознания, заполняя новое политическое пространство, необходимость охвата которого не была вовремя осознана. Для него характерно инициативное происхождение «снизу», наступательный активный характер и способность к созданию коалиций для совместных действий.

Наблюдаются явно выраженные тенденции развития женского движения в США. Об этом свидетельствуют вовлеченность в политический процесс и законотворческую деятельность; межсекторное взаимодействие с властью, бизнесом, научными кругами, а также с политическим партиями; поиски контактов и партнерств внутри самого гражданского общества; внимание к проблемам консолидации и сетевого строительства; ориентированность на локальный уровень гражданской деятельности.

Вместе с тем, по мнению американских экспертов, конституционные права женщин (ослабление защиты от насилия по признаку пола), репродуктивные права (репродуктивная автономия, «нападки» на репродуктивные права, подрыв законных прав женщин) подвергаются опасности. И наконец, администрации Д. Трампа вменяют в вину подрыв лидерства женщин. Многочисленные марши протеста в Международный женский день в США и во многих странах стали одной из крупнейших протестных акций в истории. Акция солидарности, проходившая во всем мире под хэштегом «Я тоже» (\#МеТоо) привлекла внимание к масштабу сексуального насилия и домогательств.

При этом в американском обществе наблюдается понимание того, что развитие партнерства в политике объективно зависит от уровня партнерства в социальноэкономической модели общества в целом, и наоборот. Процесс взаимосвязан. 
Вот почему осознана необходимость развивать новый социальный контракт, в котором мужчины и женщины работают на паритетных началах, дополняя друг друга, обогащая друг друга благодаря своим различиям. Кроме того, требуется такое разделение ответственности, которое ликвидирует нарушения равновесия, существующие в общественной и частной жизни. Для того чтобы развиваться, обществу необходимо использовать все свои ресурсы и всех своих членов, что означает полное и всеобъемлющее участие женщин и мужчин в общественнополитических процессах.

\section{References}

Access Denied: Origins of the Hyde Amendment and Other Restrictions on Public Funding for Abortion (2017), available from https://www.aclu.org/other/access-denied-origins-hydeamendment-and-other-restrictions-public-funding-abortion (accessed 09.02.2018).

America First: A Budget Blueprint to Make America Great Again (2018), available from https://www.whitehouse.gov/wp-content/uploads/2017/11/2018_blueprint.pdf (accessed 09.03.2018).

Cooney, Ch. (2017) How the Trump Administration Is Defunding Women and Girls Worldwide, Planned Parenthood, 4th April, available from https://www.plannedparenthoodaction.org/ blog/how-the-trump-administration-is-defunding-women-and-girls-worldwide (accessed 09.03.2018).

Frothingham, S., Phadke, S. (2017) 100 Days, 100 Ways the Trump Administration Is Harming Women and Families, available from https://www.americanprogress.org/issues/ women/reports/2017/04/25/430969/100-days-100-ways-trump-administration-harmingwomenfamilies/ (accessed 27.04.2017).

Hartmann, H. et al. (2015) How the New Overtime Rule Will Help Women \& Families, Washington: Institute for Women's Policy Research, available from https:/iwpr.org/wp-content/uploads/ wpallimport/files/iwpr-export/publications/Women\%20and\%20Overtime\%20(Final).pdf (accessed 11.03.2018).

Levey, N. (2017) Trump budget envisions big cuts for health and human services, Los Angeles Times, 16th March, available from http://www.latimes.com/politics/washington/ la-na-essential-washington-updates-trump-budget-envisions-big-cuts-for-1489664310htmlstory.html (accessed 18.03.2017).

Levintova, H. (2017) In One Executive Order, Trump Revoked Years of Workplace Protections for Women, available from http://www.motherjones.com/politics/2017/04/trump-justrevoked-protections-women-workplace (accessed 27.05.2017).

Mai-Duc, Ch. (2015) Obama's New Overtime Rules: How They'd Work and Who They'd Affect, available from http://www.latimes.com/business/la-fi-obama-overtime-rulesexplainer-20150630-htmlstory.html (accessed 09.02.2018).

Measuring the Impact of the Boys and Girls Clubs: 2016 National Outcomes Report (2016), available from https://www.bgca.org/about-us/club-impact (accessed 27.04.2017).

National Center for Education Statistics (2015), table 318.30: Bachelor's, Master's, and Doctor's Degrees Conferred by Postsecondary Institutions, by Sex of Student and Discipline, division 2013-14: 2015 Digest of Education Statistics, available from https://nces.ed.gov/programs/digest/d15/tables/dt15_318.30.asp?current=yes (accessed 27.05.2017). 
Park, E., Solomon, J., Katch, H. (2017) Updated House ACA Repeal Bill Deepens Damaging Medicaid Cuts for Low-Income Individuals and Families, available from http://www.cbpp.org/research/health/updated-house-aca-repeal-bill-deepens-damagingmedicaid-cuts-for-low-income (accessed 08.06.2017).

Статья поступила 09.09.2018 г.

\section{Информация об авторе / Information about the author}

Шведова Надежда Александровна - доктор политических наук, профессор, руководитель Центра социально-политических исследований, Институт США и Канады PAН, г. Москва, Россия, n.shvedova2015@yandex.ru (Dr. Sc. (Political Sc.), Professor, Head of the Center for Social and Political Studies, Institute for U.S. and Canadian Stadies of the Russian Academy of Sciences, Moscow, Russian Federation). 